\title{
RUANG KELAS SEKOLAH DASAR SEBAGAI HUNIAN SEMENTARA DI KAWASAN RAWAN GEMPA DI SELATAN JAWA
}

\author{
Rita Laksmitasari Rahayu, M.T ${ }^{1}$ \\ ${ }^{1}$ Universitas Indraprasta PGRI, Program Studi Arsitektur \\ ritalaxmi@gmail.com
}

\begin{abstract}
:
School building that has the function as a elementary school, also has the function as a temporary housing (hunian sementara/huntara). It has to have the requirements on buildings' solidity against earthquake and also the requirements for classrooms so that the space can be used with safety and comfort. The building's power in overcoming failures that happen on the wall has to be a requirement for durability against earthquake, among them is the power of overcoming ductility failure perpendicularly and shear failure. Efficiency of material usage and column positioning are the reasoning behind calculation of columns' distance in the classroom. The requirements for the room include the visibility for the students towards the teacher and whiteboard and the teacher's ability on being mobile inside the class. Those requirements are also the considerations taken into account for classroom area calculation. Huntara module unit $(2 \times 2,5) \mathrm{m} 2$ is calculated to generate the minimum area for shelter in emergency situation but with safety and comfort. Huntara module unit is adapted by considering the area measurement of the classroom that has met the requirements for building solidity against the earthquare and comfortable usage of space by user. The size of a class is $(7,5 \times 5) \mathrm{m} 2$ for 28 students and can be converted into 6 huntara module unit.
\end{abstract}

Key Words: Fokus, Erathquake, Huntara, Column, Module

\begin{abstract}
Abstrak :
Bangunan sekolah sebagai bangunan hunian sementara selain memiliki fungsi sebagai sekolah dasar juga sebagai hunian sementara (huntara), untuk itu dilihat dari syarat kekokohan bangunan terhadap gempa bumi dan juga syarat keruangan sehingga ruang kelas dapat digunakan dengan aman dan nyaman. Kekuatan bangunan dalam mengatasi kegagalan lentur tegak lurus bidang dinding dan kegagalan geser di bidang dinding sebagai syarat ketahanan bangunan terhadap gempa bumi. Efisiensi penggunaan material pada bangunan sekolah dan perletakkan kolom praktis menjadi latar belakang jarak kolom pada ruang kelas. Pada syarat keruangan, jarak pandang siswa pada guru papan tulis dan penguasaan kelas dalam kegiatan belajar oleh guru juga menjadi pertimbangan menentukan luas ruang kelas. Modul unit huntara $(2 \times 2,5) \mathrm{m} 2$ dihitung seminimal mungkin untuk tidur dalam keadaan darurat tetapi masih aman dan nyaman. Jumlah modul unit huntara disesuaikan dengan luas ruang kelas yang telah ditetapkan yang berdasarkan kekokohan bangunan terhadap gempa bumi dan kenyamanan penggunaan ruang oleh pengguna. Ukuran kelas $(7,5 \times 5) \mathrm{m} 2 \mathrm{untuk}$ menampung 28 siswa dan 6 modul unit huntara.
\end{abstract}

Kata Kunci : Fokus, Gempa, Huntara, Kolom, Modul.

\section{PENDAHULUAN}

Empat tahun terakhir (2014-2018) gempa di Indonesia dengan Magnitude Range 5-9,5 SR dan Depth Range 1-300 km, terbanyak terjadi di Jawa terutama selatan Jawa yaitu 57 kali gempa (BMKG, 2018). Sebagai langkah mitigasi bencana, Indonesia membutuhkan hunian dan fasilitas umum yang aman terhadap bencana terutama bencana alam gempa bumi. Korban bencana alam gempa bumi biasanya mengungsi pada hunian sementara (huntara) di beberapa fasilitas umum yaitu: sekolah, tempat ibadah, gedung pertemuan, gedung pemerintahan. Dari ke 4 fasilitas umum tersebut, yang terbanyak mengalami kerusakan adalah gedung sekolah.
Pada satu desa atau kelurahan biasanya memiliki lebih dari satu gedung sekolah yang kemungkinan besar gedung sekolah tersebut dapat digunakan sebagai hunian sementara (huntara) korban bencana alam gempa bumi. Sebagai salah satu fasilitas umum yang termasuk dalam program mitigasi bencana, sekolah wajib memenuhi syarat: fasilitas, manajemen, pendidikan pencegahan dan pengurangan risiko bencana. Di daerah rawan gempa Indonesia terdapat 136.640 sekolah yang terdiri dari 109.401 SD dan 18.855 SMP, 7.237 SMA, dan 1.146 SLB setidaknya terdapat 221 kabupaten di Aceh, Jawa Bagian Selatan, Bali, Nusa Tenggara, Maluku, Sulawesi, Sangihe Talaud. (Rosmha Widiyani, 2017). Bangunan 
sekolah yang berfungsi sebagai huntara harus memenuhi syarat keamanan dan kenyamanan (keandalan bangunan) terhadap bencana alam gempa bumi di daerah rawan gempa. Tinjauan bangunan evakuasi sebagai hunian sementara (huntara) adalah jalur evakuasi, tata ruang, fasilitas sebagai bangunan evakuasi bencana yang mampu menampung korban bencana alam gempa bumi. Lokasi tinjauan ini berada di daerah LebakPandeglang Banten.

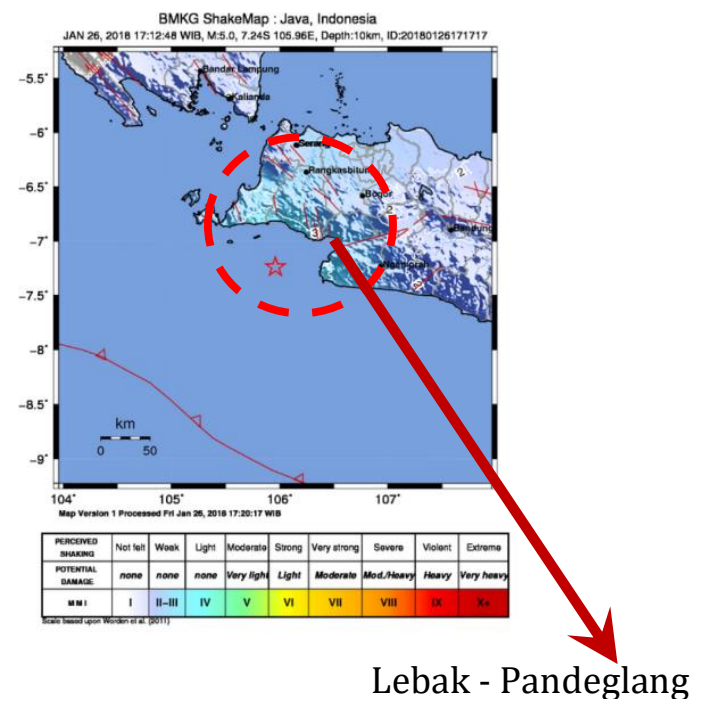

Gambar 1. Lokasi Lebak-Pandeglang

Berdasarkan SNI Perencanaan Ketahanan Gempa Gedung nomor 1726 tahun 2002, terlihat peta gempa bumi Indonesia terbagi dalam 6 Wilayah Gempa, dimana Wilayah Gempa 1 adalah wilayah dengan kegempaan paling rendah dan Wilayah Gempa 6 dengan kegempaan paling tinggi. Lebak-Pandeglang termasuk dalam wilayah kegempaan tinggi, yaitu wilayah gempa 5. Pembagian Wilayah Gempa ini, didasarkan atas percepatan puncak batuan dasar akibat pengaruh Gempa Rencana dengan perioda ulang 500 tahun, yang nilai rata-ratanya untuk setiap Wilayah Gempa. Kerusakan bangunan akibat gempa sangat beragam mulai dari kerusakan ringan-slight damage (skala MMI VI) dimana bagian non struktur bangunan mengalami kerusakan ringan, seperti retak rambut pada dinding, genteng bergeser ke bawah dan sebagian berjatuhan skala MMI XII yaitu sebagian besar bangunan permanen roboh. Struktur bangunan mengalami kerusakan berat. Skala Modified Marcalli Intencity (MMI) adalah satuan untuk mengukur kekuatan gempa bumi
(www.bmkg.go.id:2018)

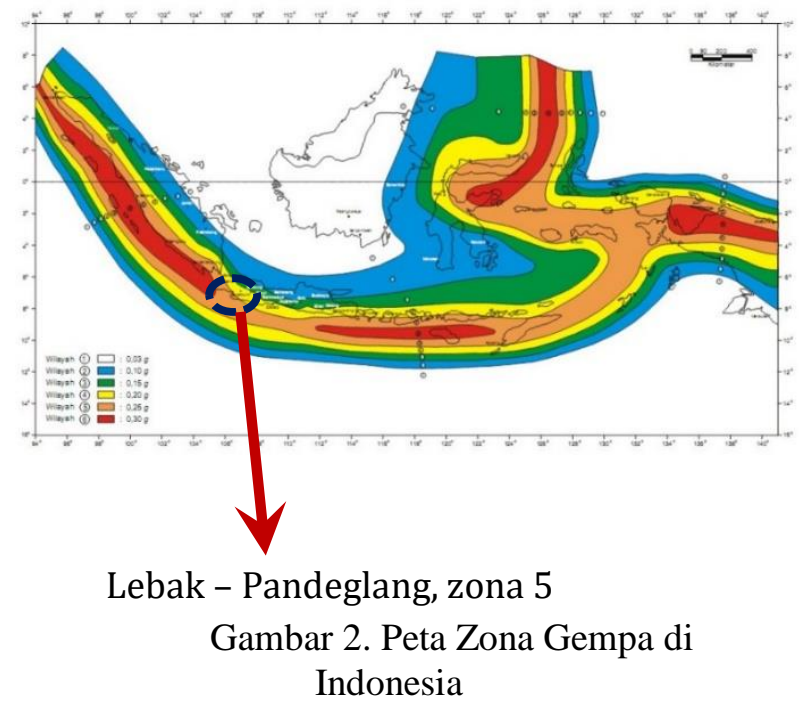

Bangunan sekolah sebagai bangunan tahan gempa, ditinjau juga sebagai huntara yang memiliki nilai keandalan bangunan. Kemungkinan adanya tambahan fungsi baru sebagai huntara bencana alam gempa bumi, maka bangunan sekolah tersebut harus sesuai dengan UU No 28 tahun 2002 tentang bangunan gedung, PPIUG 1983 tentang Peraturan Pembebanan Indonesia untuk Gedung, SNI 2847:2013 tentang persyaratan beton struktural untuk bangunan gedung, SNI 1726:2012 tentang tata cara perencanaan ketahanan gempa untuk struktur bangunan gedung dan non gedung, dan Pedoman Teknis Bangunan Sekolah Tahan Gempa. Struktur bangunan harus rigid dan kokoh; kolom-kolom dan balok-balok menyalurkan beban dan dinding bekerjasama dengan kolom-balok menahan beban dari atap menuju elemen struktur di bawahnya. Setiap elemen struktur satu sama lain pada bangunan tersambung dengan baik dan benar.

Untuk dapat membangun bangunan tembokan tahan gempa, ada beberapa masalah yang harus dipertimbangkan. Kalau bangunan didesain secara elastik, dinding-dinding berperan sebagai diafragma, jadi harus kaku. Tujuan dinding tembokan adalah untuk membagi beban-beban tegak lurus dinding ke dinding yang sejajar beban melalui dinding-dinding tersebut. Sambungan yang baik akan menghasilkan kesinambungan struktural yang dapat memindahkan gaya-gaya dinamis antarelemen struktural. (Boen,2016). Tujuan utama membangun bangunan tahan gempa adalah: 1. Menyelematkan nyawa manusia, 2. Mengurangi secara maksimal kecelakaan yang 
bakal terjadi dan harta benda, 3. Mengurangi sebesar mungkin biaya yang harus dikeluarkan bila melakukan perbaikan. Kekokohan bangunan terhadap gempa bumi dengan memperhatikan: 1 . Tidak mengalami kerusakan pada saat dilanda gempa ringan, 2. Tidak mengalami kerusakan struktur tapi mungkin mengalami kerusakan non struktur pada saat dilanda gempabumi sedang, 3 . Bila terkena gempa bumi maksimum, mungkin terjadi dengan periode ulang yang telah ditetapkan: a. bangunan boleh mengalami kerusakan struktur maupun non struktur tapi tidak boleh runtuh sebagian atau seluruhnya, b. bangunan tersebu tidak boleh mengalami kerusakan yang tidak dapat diperbaiki, c. bangunan boleh mengalami kerusakan tetapi kerusakan yang terjadi harus dapat diperbaiki dengan cepat sehingga dapat berfungsi kembali. (Boen,2000)

\section{Sekolah}

Kegagalan bangunan sekolah disebabkan oleh mutu bahan yang rendah, mutu pengerjaan rendah, detail yang tidak tepat dan tidak memadai, dan kurang perawatan. Bangunan sekolah harus diuat kuat karena beberapa alasan, yaitu (Boen, 2016; Federal Emergency Management Agency, 1990)

1. Robohya gedung sekolah dalam menyebabkan korban jiwa.

2. Sebagian besar penghuni adalah anak-anak yang merupakan sumber daya berharga di masyarakat.

3. Bangunan sekolah dapat berfungsi sebagai tempat penampungan setelah gempa dengan demikan, bangunan sekolah adalah asset yang berharga.

4. Penutupan sekolah untuk waktu yang lama dapat menyebabkan masalah dalam masyarakat dan kerusakan parah bangunan sekolah dapat menyebabkan masalah ekonomi jangka panjang.

5. Di Indonesia, berdasarkan kebiasaan membangun sekolah, biaya tambahan untuk bangunan baru agar tahan gempa relatif kecil sekitar $1,5 \%$ dari biaya konstruksi

6. Untuk bangunan sekolah, kalau direncanakan dan dibangun dengan benar akan sebanding dengan manfaat yang diperoleh.

Jumlah kelas yang harus disediakan pada satu SD harus sesuai dengan Peraturan Menteri Pendidikan dan Kebudayaan. Kapasitas siswa dalam 1 lokal minimal 20 siswa sampai 28 siswa (pasal 24 (a)) dan jumlah rombongan belajar (rombel) setiap sekolah 6 rombel-24 rombel pasal 26 (a).
(Permendikbud no 17 tahun 2017). Jumlah siswa setiap sekolah 120 siswa sampai 675 siswa. Dimensi ruang lokal $8 \times 8 \mathrm{~m} 2$ dengan terdapat delatasi $10 \mathrm{~cm}$ setiap 2 kelas. Hal ini untuk mengoptimalkan potensi gaya inersia bangunan agar dapat mengimbangi dan meredam gaya gempa yang terjadi pada bangunan.

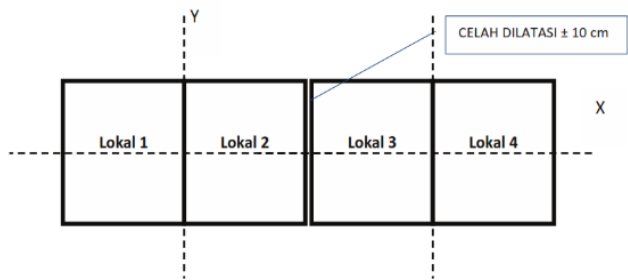

Gambar 3. Letak Ruang-Ruang Simetris dengan Perbandingan P:L $=2: 1$

Sumber: Pedoman Teknis Bangunan Sekolah Tahan Gempa

Jika bangunan tidak simetris, maka setiap perubahan arah (orientasi) lokal dapat dipisahkan secara struktur. Hal ini juga bertujuan mengoptimalkan potensi gaya inersia bangunan agar dapat mengimbangi dan meredam gaya gempa yang terjadi pada bangunan. Pembahasan ini yaitu sekolah dasar tidak bertingkat dengan struktur rangka-dinding pasangan bata.

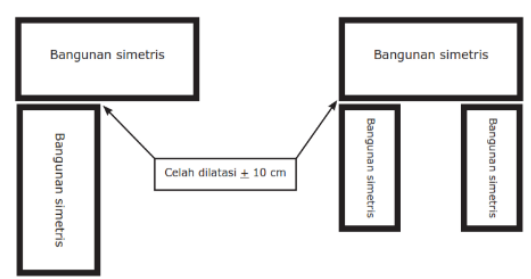

Gambar 4. Gunakan Delatasi pada Pemisahan Orientasi Lokal

Sumber: Pedoman Teknis Bangunan Sekolah Tahan Gempa

\section{Struktur Bangunan}

Kegagalan bangunan tembokan terhadap gempa bumi akibat goncangan gempa terutama disebabkan oleh kegagalan lentur tegak lurus bidang dinding, dan/atau kegagalan geser di bidang dinding. Untuk mengatasi kegagalan bangunan tembokan, harus ada penjangkaran antara dinding dengan bingkai rangka sekeliling dinding. Akibat adanya beban vertical dan horizontal dapat direspon baik jika terdapat bingkai balok sekeliling bidang dinding sehingga kegagalan lentur tegak lurus bidang dinding dapat dihindari dan meningkatkan stabiltas "rocking" tegak lurus bidang dinding tersebut. Kemungkinan terjadi kegagalan lentur juga dipengaruhi oleh rasio kelangsingan dinding. Rasio kelangsingan adalah ukuran kecenderungan suatu elemen yang 
ditekan akan gagal akibat tekuk sebelum terjadi kegagalan akibat kehancuran. Gaya gempa yang bekerja pada dinding secara horizontal atau gerakan di bidang dinding tidak merusak bangunan seperti gerakan gempa tegak lurus bidang. Kemungkinan terjadi jika bata lemah tetapi adukan kuat, atau sebaliknya bata kuat tetapi adukan lemah akan terjadi retakan secara diagonal dinding pada siar. Pergeseran dinding berupa kegagalan geser atau slip searah gerakan gempa terdapat pada siar lekatan antarbata. Bangunan tembokan berdiding tebal pada umunya tetap stabil dan masih memiliki karakteristik stabilitas setelah retak sepenuhnya terbentuk (Boen, 2016).

Bangunan sekolah terletak di atas tanah yang stabil dengan memenuhi persyaratan sebagai berikut:

a. Denah bangunan sederhana dan simetris.

b. Sloof diangkur ke pondasi.

c. Gunakan bahan struktur atap dan penutup atap yang ringan, apabila menggunaan konstruksi kayu gunakan kayu yang kering.

d. Dinding bata dipasang angkur setiap jarak vertikal $30 \mathrm{~cm}$ yang dijangkar pada kolom.

e. Setiap luasan dinding $9 \mathrm{~m} 2$ harus dipasang kolom praktis

f. Dipasang balok ring yang diikat kaku dengan kolom

g. Seluruh kerangka bangunan harus diikat secara kokoh dan kaku.

h. Komposisi bahan adukan beton adalah 1 semen: 2 pasir: 3 kerikil

i. Setiap penggunaan 1 zak semen diperlukan kira-kira 5 ember (25 liter) air untuk adukan beton

j. Pelaksanaan dengan pendampingan tukang yang berpengalaman.

(Pedoman Teknik Sekolah Tahan Gempa)

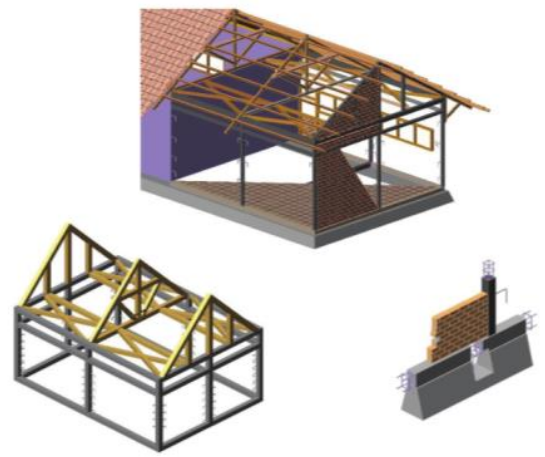

Gambar 5. Struktur Rangka dengan Dinding Pemikul Pasangan Bata

Sumber: Pedoman Teknis Bangunan Sekolah Tahan Gempa
Gaya luar yang bergerak secara horisontal ke arah sisi pendek bangunan diperkuat dengan pemasangan kolom praktis dengan jarak yang baik. Jarak antar kolom yang terlalu panjang memperlemah kekuatan bangunan sehingga tidak dapat meredam gaya akibat gempa.

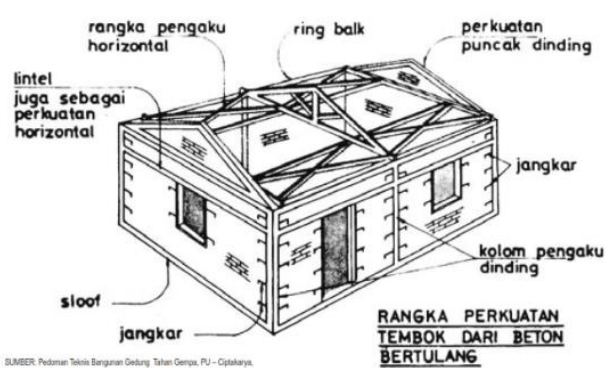

Gambar 6. Kolom Pengaku Dinding Ada dengan Jarak yang Cukup

Sumber: Pedoman Teknis Bangunan Sekolah Tahan Gempa

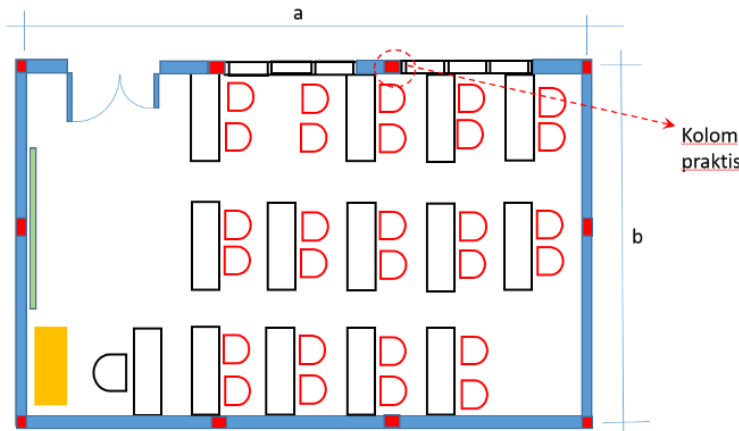

Gambar 7. Penambahan Kolom Pada Sisi Panjang Ruang

\section{Ruang Kelas}

Ruang kelas sebagai wadah kegiatan pembelajaran dengan metoda ceramah banyak digunakan pada sekolah di Indonesia, begitu pula dengan Sekolah Dasar. Kegiatan pembelajaran adalah interaksi antara peserta didik dan guru, peserta didik dengan peserta didik, dan peserta didik dengan sumber belajar untuk mencapai kompetensi yang diharapkan. (Permendikbud 103 tahun 2014 dan Permendikbud 22 tahun 2016). Kegiatan ini harus dapat diwadahi dalam ruang kelas yang cukup dan sesuai dengan keandalan bangunan. Keselamatan, kemudahan, kesehatan, dan kenyamanan pengguna kelas menjadi prioritas utama pada proses pembelajaran ini. Penataan kelas Sekolah Dasar untuk mendapatkan hasil belajar mengajar yang baik menurut Loisell (dalam Winataputra, 2003): yaitu :

1. Visibility (keleluasaan pandangan) 
2. Accesbility (kemudahan pencapaian)

3. Fleksibilitas ruang (keluwesan)

4. Kenyamanan

5. Keindahan

Metoda ceramah pada proses belajar, guru sebagai pusat perhatian peserta didik. Bentuk ruang dengan bentuk aktivitas tersebut setengah lingkaran dengan guru sebagai titik pusatnya. Efekifitas dan efisiensi penggunaan ruang dengan bentuk setengah lingkaran sulit terwujud karena bentuk furniture yang persegi panjang. Pola gerak manusia untuk menjangkau sesuatu berbentuk setengah lingkaran, tetapi perlengkapan yang digunakan berbentuk persegi panjang. Transformasi bentuk setengah lingkaran dan pendekatan furniture yang digunakan (meja) dan perlengkapan yang digunakan berbentuk persegi panjang maka bentuk ruang kelas dengan metoda ceramah memiliki bentuk empat persegi panjang.

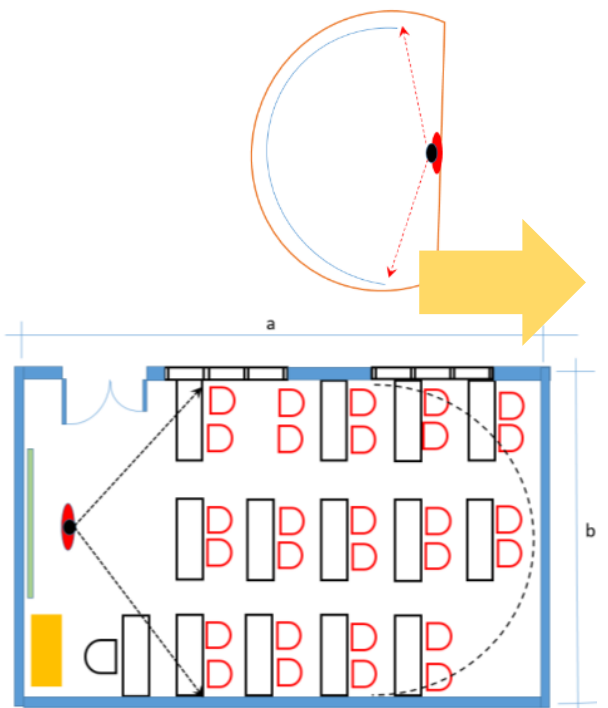

Gambar 8. Transformasi Bentuk Kelas

Selain keluasan ruang bagi guru dalam menguasai kelas, perlu juga diperhatikan jarak pandang siswa terhadap papan tulis, baik secara horisontal maupun ketinggian papan (vertical). Jarak terjauh siswa $<9$ meter dan sudut kemiringan pandangan siswa maksimal $30^{\circ}$. (Ahlstrom \& Kudrick, 2007)

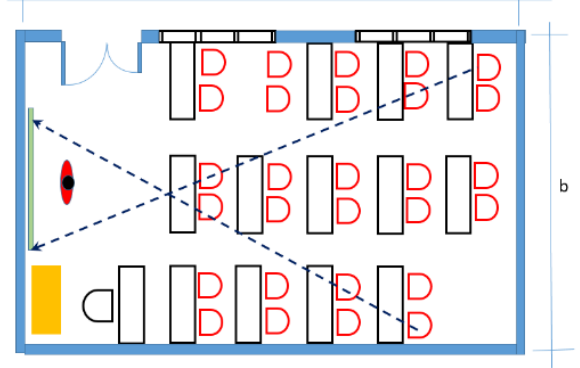

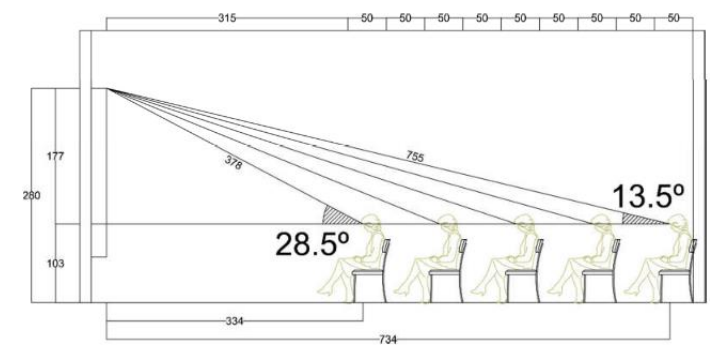

Gambar 9. Jarak Pandang Siswa terhadap Papan Tulis

\section{Ruang Hunian Sementara}

Pengungsi di hunian sementara (huntara) melakukan aktivitas sehari hari, untuk itu ruang pada huntara harus dapat mewadahi aktivitas tersebut. Termasuk efisiensi dan efektivitas penyimpanan sementara furniture ruang kelas selama digunakan sebagai huntara. Jenis kegiatan sehari-hari yang ditampung pada unit huntara adalah tidur dan menyimpan kebutuhan keluarga. Kegiatan lain seperti memasak, makan dan mandi dilakukan di luar unit tersebut. Banyak kegiatan yang dilakukan secara bersama sehingga membutuhkan ruang komunal, seperti dapur umum, ruang bermain, ruang makan, dan ruang serba guna. Ruang-ruang tersebut dapat diletakkan pada ruang di dalam bangunan semi permanen dan ruang luar. Luas kebutuhan ruang setiap modul per keluarga ( 2 anak) 2 × 2,5 meter persegi, termasuk tempat penyimpanan keperluan setiap keluarga ditambah ruang sirkulasi $20 \%$.

\section{METODOLOGI}

Metode penelitian yang digunakan adalah dekriptif eksploratif, dengan pendekatan bangunan sekolah tahan gempa, yang terdiri dari syarat bangunan tahan gempa, syarat keruangan, dan obyek. Pada bangunan tahan gempa terdapat perencanaan : ruang dan bangunan tahan gempa. Pada syarat bangunan tahan gempa terdiri dari perencanaan elemen struktur, system struktur dan metoda konstruksi yang digunakan. Pada syarat keruangan, memperhatikan aktivitas pengguna, kebutuhan ruang, dan dimensi ruang. Sedangkan pada lokasi berupa obyek yang akan ditinjau baik dalam ruang, bangunan, maupun fasilitas. 


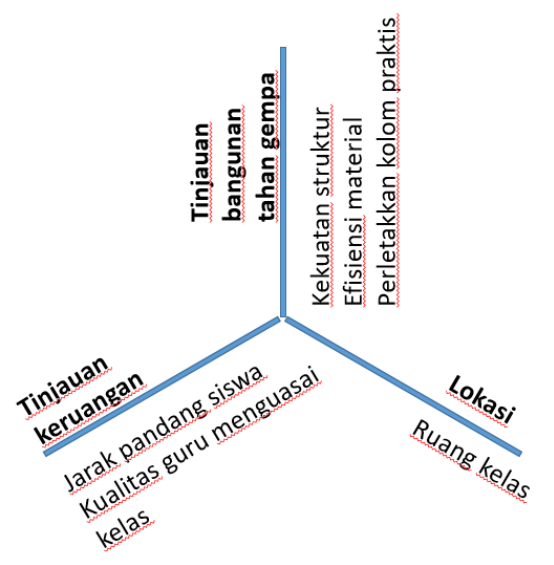

Gambar 10. Elemen-Elemen Pengukuran Kajian Bangunan Sekolah

Proses perencanaan bangunan tahan gempa terdapat beberapa tahap yaitu: indikasi, investigasi, dan diagnosa. Pengumpulan data menggunakan teknik observasi ruang.

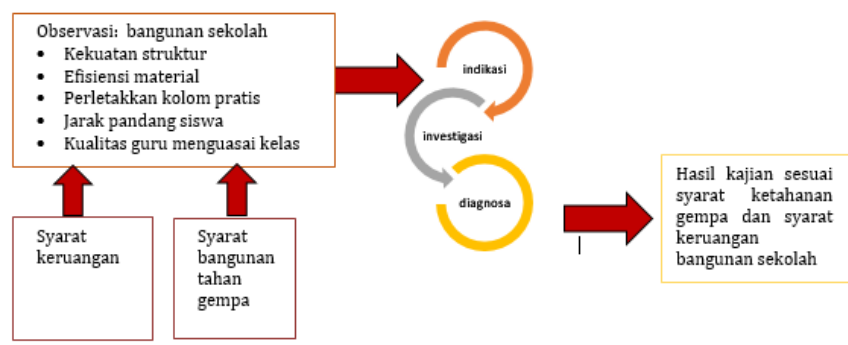

Gambar 11. Kerangka Berpikir

\section{HASIL DAN PEMBAHASAN}

Kondisi bangunan sekolah terutama Sekolah Dasar di daerah rawan gempa, harus memiliki kelebihan lain yaitu kekokohan dan kekuatan terhadap bencana gempa bumi. Bangunan gedung memiliki struktur yang stabil dan kukuh sampai dengan kondisi pembebanan maksimum dalam mendukung beban muatan hidup dan beban muatan mati, serta untuk zona tertentu kemampuan untuk menahan gempa dan kekuatan alam lainnya (permendiknas nomor 24 tahun 2007).

Ukuran ruang kelas dapat menampung maksimal 28 orang siswa dan dapat beraktivitas belajar mengajar dengan baik. Modul ruang sesuai dengan kekuatan struktur terhadap kegagalan lentur dan kegagalan geser, semakin pendek jarak panjang kelas maka bangunan akan semakin kokoh merespon gaya gempa. Efisiensi material yang digunakan dengan modul 2,5 meter dan perletakkan kolom praktis. Jarak pandang siswa terhadap papan juga masih dalam jarak yang nyaman $\left(<30^{\circ}\right)$. Ruang kelas yang lebih kecil dengan ukuran yang cukup akan memberikan dampak guru semakin mudah menguasai kelas dan siswa dapat lebih fokus.

Tabel 1. Perbandingan Jarak Kolom Praktis

$\begin{array}{ll}\text { Jarak kolom } & \text { Jarak } \\ \text { praktis } & \text { kolom } \\ \text { kurang dari } & \text { praktis } \\ (3 \times 3) \mathrm{m}^{2} & \begin{array}{l}\text { lebih dari } \\ (3 \times 3) \mathrm{m}^{2}\end{array} \\ & \end{array}$

Kekuatan struktur

terhadap kegagalan

lentur dan

kegagalan geser

\begin{tabular}{lll}
\hline Efisiensi material & $\sqrt{ }$ & - \\
\hline $\begin{array}{l}\text { Perletakkan kolom } \\
\text { praktis }\end{array}$ & $\sqrt{ }$ & - \\
\hline $\begin{array}{l}\text { Jarak pandang } \\
\text { siswa terhadap }\end{array}$ & $\sqrt{ }$ & - \\
papan menguasai & $\sqrt{ }$ & - \\
\hline $\begin{array}{l}\text { Guru melas dan siswa } \\
\text { lebih fokus. }\end{array}$ & & \\
\hline
\end{tabular}

Jarak pandang siswa maksimal 7 meter ke arah papan tulis begitu pula dimensi ruang bagi guru dalam menguasai kelas. Ruang yang tidak terlalu besar dan dapat dikuasai dengan baik oleh guru memberikan dampak positif bagi proses belajar. Aktivitas siswa di dalam kelas: mendengarkan, menulis, membaca, mengerjakan tugas, dan berdiskusi. Aktivitas guru di dalam kelas: menjelaskan, menulis di papan tulis, menulis, membaca, mendengarkan. Fasilitas yang digunakan siswa: meja, kursi, alat peraga. Fasilitas yang digunakan guru: meja, kursi, papan tulis.

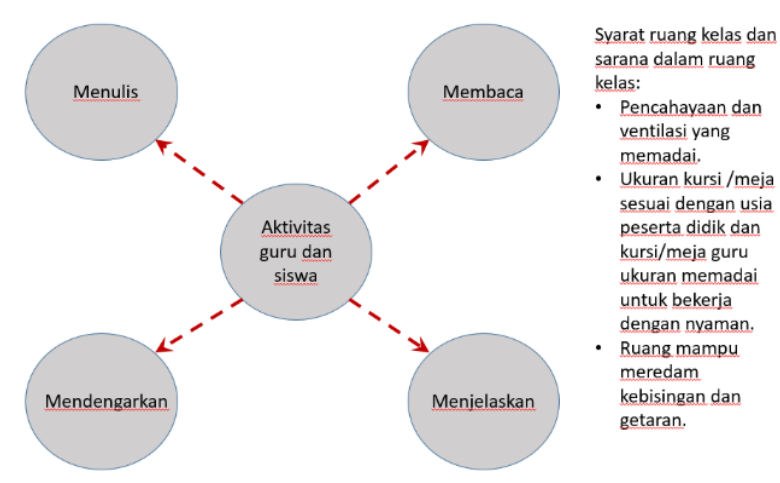

Gambar 12. Syarat Ruang Terhadap Aktivitas Pengguna 
Selain sebagai ruang belajar, kelas juga harus mampu menjadi ruang penampungan bagi pengungsi. Luas ruang kelas harus dapat menampung pengungsi dengan memperhatikan keandalan bangunan. Setiap ruang kelas setidaknya dapat menampung 6 kepala keluarga (2 anak) dengan cukup nyaman. Setiap sekolah minimal memiliki 6 rombel, sehingga jumlah kepala keluarga yang dapat ditampung sebanyak 36 kepala keluarga, jika sekolah tersebut memiliki 36 rombel maka jumlah kepala keluarga yang dapat ditampung sebanyak 1296 kepala keluarga. Luas kebutuhan ruang setiap modul per keluarga (2 anak) 2 x 2,5 meter persegi, termasuk tempat penyimpanan keperluan setiap keluarga ditambah ruang sirkulasi $20 \%$. Enam modul unit huntara $2,5 \times 2,5$ meter persegi ditampung pada setiap ruang kelas.

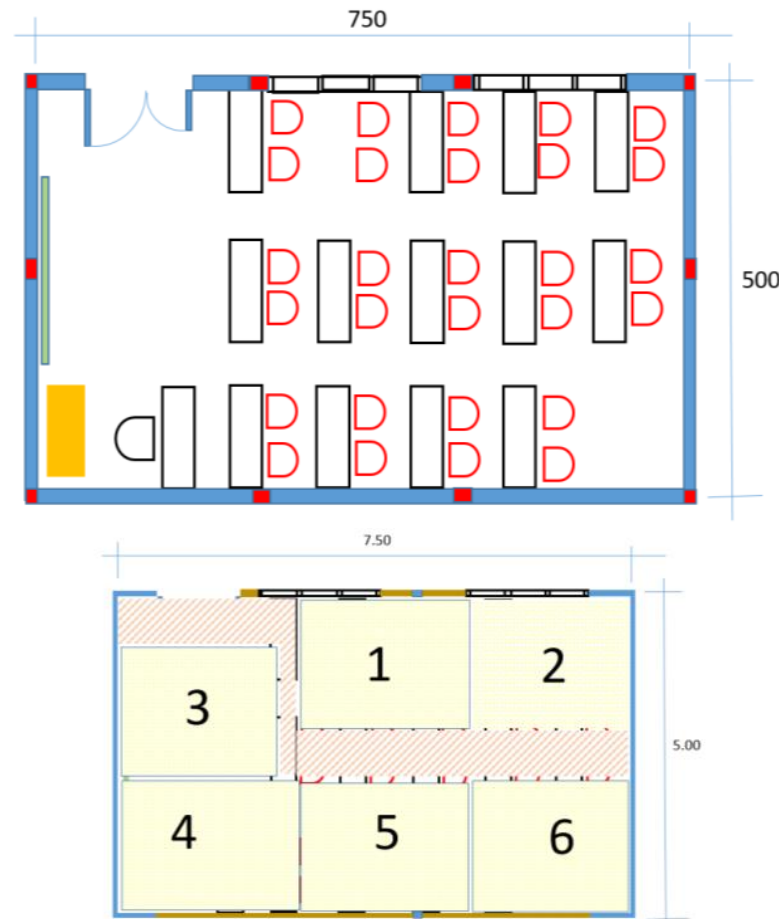

Gambar 13. Ukuran Ruang sebagai Kelas dan Unit Huntara

Kekakuan bangunan sekolah harus memperhatikan struktur yang digunakan, yaitu struktur rangka dengan letak dan dimensi elemen struktur sesuai dengan perhitungan dan kaidah yang berlaku. Bentuk ruang yang sederhana, membantu kekakuan bangunan. Ruang kelas terbuat dari bata yang diikat menggunakan kolom dan balok beton. Jarak antarkolom (kolom praktis) 2,5 meter dan dimensi penampang kolom (15x15) sentimeter persegi dan ketebalan dinding 1 bata sehingga dapat menjadi solusi terhadap kegagalan lentur tegak lurus bidang dinding dan kegagalan geser di bidang dinding.

\section{PENUTUP}

\section{Simpulan}

1. Perencanaan bangunan sekolah sebagai bangunan tahan gempa merupakan hal yang sangat penting di Indonesia terutama daerah rawan gempa.

2. Ukuran ruang kelas dihitung sesuai dengan kekuatan bangunan terhadap kegagalan lentur tegak lurus dinding dan kegagalan geser di dinding, maka jarak kolom praktis maksimal 3 meter.

3. Ruang kelas yang memiliki fungsi sebagai unit huntara berukuran $(7,5 \times 5) \mathrm{m}^{2}$ dapat menampung 2 fungsi dengan baik, secara kekuatan bangunan maupun kenyamanan.

4. Enam modul unit huntara $2 \times 2,5$ meter $^{2}$ setiap keluarga ditampung pada ruang kelas berukuran $(7,5 \times 5) \mathrm{m}^{2}$

\section{Saran}

Untuk melengkapi hasil kajian ini maka kajian selanjutnya adalah;

1. Tata letak ruang-ruang di Sekolah Dasar sesuai Permendiknas nomor 24 tahun 2007 seperti ruang perpustakaan, laboratorium, ruang pimpinan, ruang guru, tepat ibadah, ruang UKS, dan lainnya. Tinjauan untuk sekolah dasar yang digunakan pula sebagai hunian sementara di daerah rawan gempa dengan pendekatan bangunan tahan gempa.

2. Efektivitas material yang digunakan sesuai dengan pendekatan dimensi ruang dan syarat kekokohan bangunan sekolah dasar pada daerah rawan gempa.

\section{DAFTAR PUSTAKA}

Ahlstrom, V.,dan Kudrick, B., 2007. Human Factors Criteria for Display s : A Human Factors Design Standard Update of Chapter 5, Departement of Transportation, Uni Soviet.

Boen, Teddy. 2016. Jogyakarta: Belajar dari Kerusakan akibat Gempa Bumi Bangunan Tembokan Nir-Rekayasa di Indonesia.

Frick H. dan Mulyani, Tri Hesti. 2006. Semarang: Pedoman Bangunan Tahan Gempa.

Muman, Dian Kumala,. dan Hadiansyah, Mahendra Nur,. 2016. "Analisis Jarak dan Sudut Pandang Posisi Duduk Pada Ruang Perkuliahan Terhadap Efektivitas belajar Mahasiswa di Gedung Tokong Nanas 
Universitas Telkom.” Jurnal Idealog, Vol 1 No 2, Agustus.

Winataputra. Udin S, 2003. "Strategi Belajar Mengajar." Jakarta: Pusat Penerbitan Universitas Terbuka.

Pedoman Teknis Bangunan Sekolah Tahan Gempa. 2010. Jakarta: Direktorat Pembinaan Sekolah Menengah Atas Direktorat Jendral Pendidikan Menengah Kementrian Pendidikan Nasional.

Peraturan Menteri Pendidikan Nasional. 2007. Jakarta: tentang standar sarana dan prasarana untuk Sekolah Dasar/Madrasah Ibtidaiyah (SD/MI), Sekolah Menengah Pertama/Madrasah Tsanawiyah (SMP/MT), Sekolah Menengah Atas/Madrasah Aliyah (SMA/MA) Menteri Pendidikan Nasional.

Peraturan Pembebanan Gedung Indonesia. 1983. Jakarta: Pekerjaan Umum-Cipta Karya.

SNI 2847. 2013. Jakarta: tentang persyaratan beton struktural untuk bangunan gedung. 2013. Jakarta: Badan Standardisasi Nasional Indonesia.

SNI 1726. 2012. Jakarta: tentang tata cara perencanaan ketahanan gempa untuk struktur bangunan gedung dan non gedung. 2012. Jakarta: Departemen Permukiman dan Prasarana Wilayah. Badan Penelitian dan Pengembangan Teknologi Permukiman.

Undang-Undang Republik Indonesia Nomor 28 tahun 2002 tentang Bangunan Gedung. 2017. Jakarta. 